\title{
The Teaching of Occlusion in Undergraduate Dental Schools in the UK and Ireland
}

\author{
O'Carroll E ${ }^{1}$, Leung $A^{1}$, Fine $P^{1}$, Boniface $D^{1}$, Louca $C^{2}$.
}

1=UCL Eastman Dental Institute, London, UK

2= University of Portsmouth Dental Academy, Portsmouth, UK

\begin{abstract}
The teaching of occlusion in undergraduate dental schools in the UK and Ireland is a cornerstone of an integrated approach to the many different clinical disciplines in dentistry. This study investigated and evaluated the teaching of occlusion in undergraduate dental schools in the UK and Ireland, the thorough understanding of which would facilitate young graduates to become competent practitioners.
\end{abstract}

\section{Material and Methods}

A mixed-methods approach was employed, with primary data generated and collected by using a cross sectional questionnaire-based survey which was followed-up by semi-structured interviews. The hard copy questionnaires enquired about: i) whether occlusion was taught, ii) how long was spent by schools teaching occlusion, iii) what teaching resources were employed, iv) tutors' perceptions of how well prepared for general practice new graduates were and v) how was knowledge/skill assessed. Follow-up interviews were undertaken with volunteering respondents to triangulate responses. Quantitative data was analysed using descriptive statistics and qualitative data was stored using the Framework Method and analysis using a thematic approach.

\section{Results}

$100 \%(n=18)$ of schools responded to the questionnaire. $66.67 \%(n=12)$ schools participated in follow-up interviews. All schools reported that they taught occlusion in their curriculum. Total hours reported teaching occlusion varied from 11 to 310 hours. $28 \%(n=5)$ of respondents reported insufficient time for the teaching of occlusion in the curriculum. There was a marked variation in: i) teaching methods, ii) resources employed, iii) assessment strategies to evaluate competency in occlusion and iv) how well prepared students were. Thematic analysis of the qualitative data identified several themes: i) variations in teaching 
pedagogy, ii) use of different resources, iii) variable assessment techniques, iv) evaluation of teaching and v) barriers to teaching occlusion.

\section{Conclusion}

This study reported on the variability in teaching occlusion between the undergraduate dental schools of the UK and Ireland. Recommendations for a coordinated teaching strategy with dedicated oversight to facilitate better student exposure to occlusion and promote student understanding of this topic is suggested.

\section{INTRODUCTION}

The teaching of undergraduate dentistry, including occlusion, is fundamental in delivering dental services to the population. Undergraduate dental students need to have a working knowledge of occlusion in order to adequately repair, restore or replace teeth, which is the responsibility of individual teaching institutes in the UK and Ireland.

The General Dental Council (GDC) oversees dental education in the UK. The GDC document 'Standards for Education. Standards and requirements for providers' 1 is a checklist for schools training dentists to provide evidence demonstrating their students' competency in a range of learning outcomes such that they can fulfil registration requirements. These learning outcomes are outlined in the GDC document 'Preparing for Practice $^{2}$, where Clinical Domain 1.14 .1 of this document states that upon registration, the registrant must be able to 'assess and manage caries, occlusion, and tooth wear'.

The Dental Council of Ireland regulates dental professionals in the Republic of Ireland. While it does not publish a document equivalent to 'Preparing for Practice', it publishes 'Learning Outcomes '3 based on the 'Profile and competences for the European dentist' ${ }^{4}$. This outlines knowledge and skills expected of dentists registering with this body. Domain IV of this document states that 'the dentist must demonstrate an ability to produce diagnostic casts, mounted and with inter-occlusal records' and Domain V states that 'the dentist must demonstrate the ability to recognize patient behaviour contributing to orofacial problems, and identifying conditions that require diagnosis, prevention and management'.

These learning outcomes or knowledge requirements, depending on the document, relate directly or indirectly to the topic of occlusion. While there is debate over the definition of 
occlusion, it essentially pertains to the area of dentistry concerned with how teeth meet, and how the jaws function as an integrated unit. Put simply, 'dentists cannot repair, move or remove teeth without being involved in occlusion'5.

The co-existence of various and apparently conflicting occlusal philosophies and disagreement regarding basic occlusal terminologies has created confusion around this topic ${ }^{6}$.

'Preparing for Practice' states that 'the principles of an evidence-based approach and the underpinning scientific knowledge are fundamental to implementing the outcomes ${ }^{2}$. This statement clearly identifies the fundamental role of an evidence-base in teaching students management of their patients' occlusion. The challenge for dental schools would therefore be to identify an appropriate evidence-based approach regarding their teaching of occlusion where diverse opinions and disagreements on nomenclature exist.

The curriculum on occlusion would need to be aligned with the appropriate learning outcomes to ensure competency and adherence to learning frameworks such as 'Standards for Education. Standards and requirements for providers'.

The teaching of occlusion in undergraduate dental schools has previously been researched in the United States ${ }^{7,8}$. Both articles recommend the need for clear, up to date guidelines for teaching occlusion at undergraduate level. They also indicate a need for "standardization of the concepts within the curriculum for occlusion due to its multifactorial nature and significant influence of expert opinions accompanied by repetitive teaching cycles, rather than evidence-based dentistry" 8 .

The aim of this study was to evaluate the teaching of occlusion in undergraduate dental schools in the UK and Ireland. The study appraised the level of exposure to occlusion teaching that students receive, the methods and resources used to teach occlusion and an overview of occlusion competency and teaching strategy in this area.

\section{MATERIALS AND METHODS}

A mixed-methods approach was employed, with primary research data generated using a cross sectional questionnaire-based survey and follow-up semi-structured interviews. 
The hard copy questionnaires enquired about: i) whether occlusion was taught, ii) how long was spent teaching occlusion, iii) what teaching resources were employed, iv) how well prepared for general practice new graduates were and v) how was undergraduates' knowledge/skill of occlusion assessed. Questionnaires were distributed by post with a covering letter to Heads of Department or Senior Lecturers/ Consultants identified as having a key input into the teaching of occlusion in each of the 18 dental schools with an undergraduate dentistry programme in the UK and Ireland. A follow-up reminder email was sent 4 weeks afterwards to those schools yet to respond, with a further reminder email two weeks subsequent to this. A code book was created using Microsoft Excel ${ }^{\circledR}$ and data from the questionnaires were imported into this spreadsheet. Ethical approval was not required for this study as per the UCL Research Ethics Committee guidelines. All data obtained was anonymised and assurances of confidentiality were made to all participants.

Follow-up interviews were conducted with respondents to triangulate responses. Written consent was obtained for interviews. Interviews were recorded using a dictaphone and Smartphone voice recorder and transcribed verbatim. Data obtained was anonymised and further assurances of confidentiality were made to all participants

The quantitative data were analysed using descriptive statistics and the qualitative data collected were analysed using the Framework Method. A thematic approach was used to detect elements and develop emerging themes.

\section{RESULTS}

Completed questionnaires were provided by all 18 undergraduate dental schools (100\%). 12 of the 18 respondents $(66.67 \%)$ agreed to a follow-up interview which was subsequently undertaken.

\section{i) Current teaching}

All respondents (100\%) reported that teaching of occlusion formed part of the prescribed curriculum in their dental schools. 


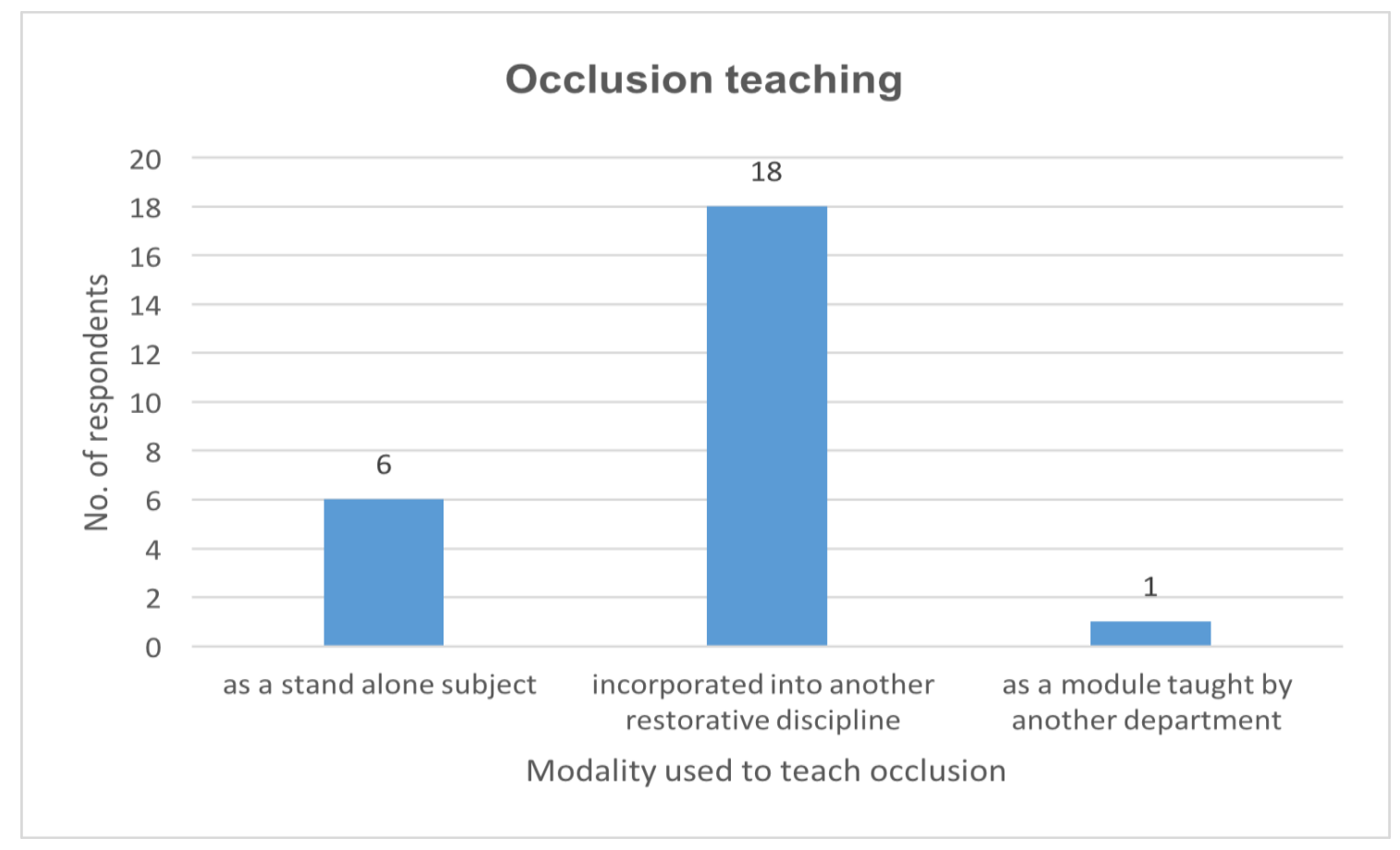

Figure.1. Modality used to teach occlusion

All schools (100\%) reported that the teaching of occlusion was incorporated into another restorative discipline. However, six schools (33.33\%) reported that occlusion was also taught as a stand-alone subject. (See Figure 1). 


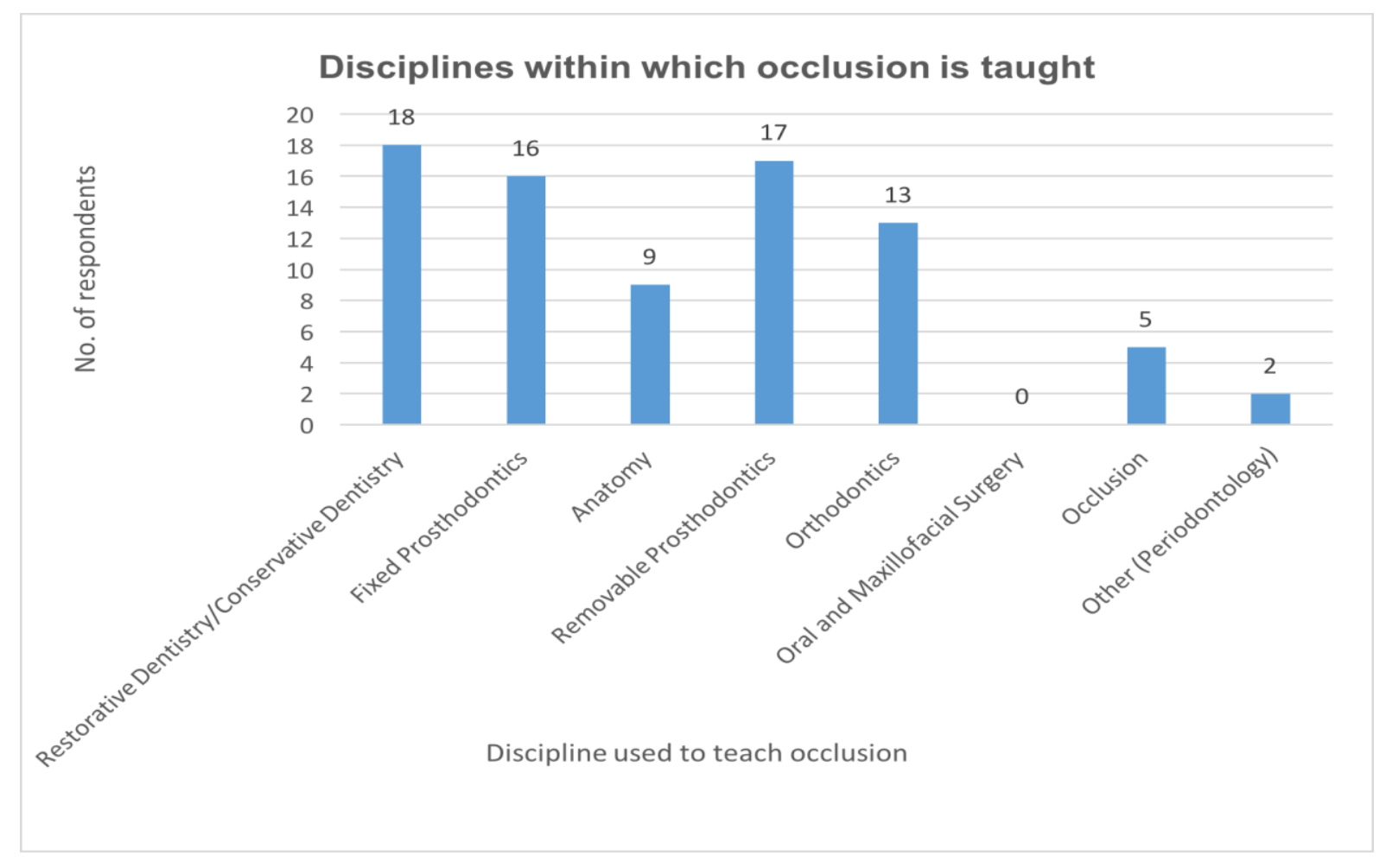

Figure.2. Disciplines within which occlusion is taught

All schools (100\%) teach occlusion within the discipline of Restorative Dentistry/

Conservative Dentistry. Schools reported a number of other disciplines where occlusion is taught (See Figure 2).

The data gained from the interviews suggests that while some schools adopt an integrated multidisciplinary approach with teacher meetings to ensure coordination, the dominant theme is a lack of coordination between departments and mono-disciplines regarding occlusion teaching. One school reported that 'it's probably taught in silos too much within the different areas', while another reported a lack of awareness regarding the teaching of occlusion by other disciplines because 'that would require us to talk to each other'. 


\begin{tabular}{|cccccc|}
\hline School ID no. & Yr1 & Yr2 & Yr3 & Yr4 & Yr5 \\
\hline 1 & - & - & - & - & - \\
\hline 2 & 1 & 10 & 20 & 0 & 0 \\
\hline 3 & 0 & 2 & 5 & 5 & 0 \\
\hline 4 & 0 & 0 & 5 & 5 & 5 \\
\hline 5 & 1 & 0 & 3 & 10 & 5 \\
\hline 6 & 0 & 6 & 10 & - & - \\
\hline 7 & 5 & 5 & 10 & 10 & 10 \\
\hline 8 & 0 & 0 & 10 & 20 & 10 \\
\hline 9 & 0 & 0 & 5 & 5 & 5 \\
\hline 10 & 0 & 10 & 10 & 10 & 0 \\
\hline 11 & - & - & - & - & - \\
\hline 12 & 1 & 1 & 5 & 5 & - \\
\hline 13 & - & - & 5 & 5 & - \\
\hline 14 & 0 & 10 & 5 & 5 & 10 \\
\hline 15 & 10 & 10 & 10 & 10 & 10 \\
\hline 16 & 5 & 5 & 8 & 9 & 10 \\
\hline 17 & - & - & - & - & - \\
\hline 18 & - & - & - & - & - \\
\hline
\end{tabular}

Table 1 Percentage (\%) of the curriculum (to nearest 10\%) spent on teaching occlusion

There was considerable variation between the schools regarding the percentage of time spent on teaching occlusion, and between the years in the different schools (See Table 1). Twelve schools $(66.67 \%)$ reported that it was difficult to estimate the percentage of time spent teaching occlusion in each year.

The varied response rate, the missing data and the difficulty schools identify in determining the percentage of time spent on teaching occlusion suggest a degree of confusion in identifying where occlusion is taught in the curriculum.

\section{ii) Hours spent teaching occlusion}

Total hours reported teaching occlusion ranged from 11 to 310 hours. This magnitude of variation suggests that different respondents have differing perceptions of what constitutes occlusion teaching. It may also infer the difficulties respondents face in accurately answering this enquiry. 
iii) Teaching resources used to teach occlusion

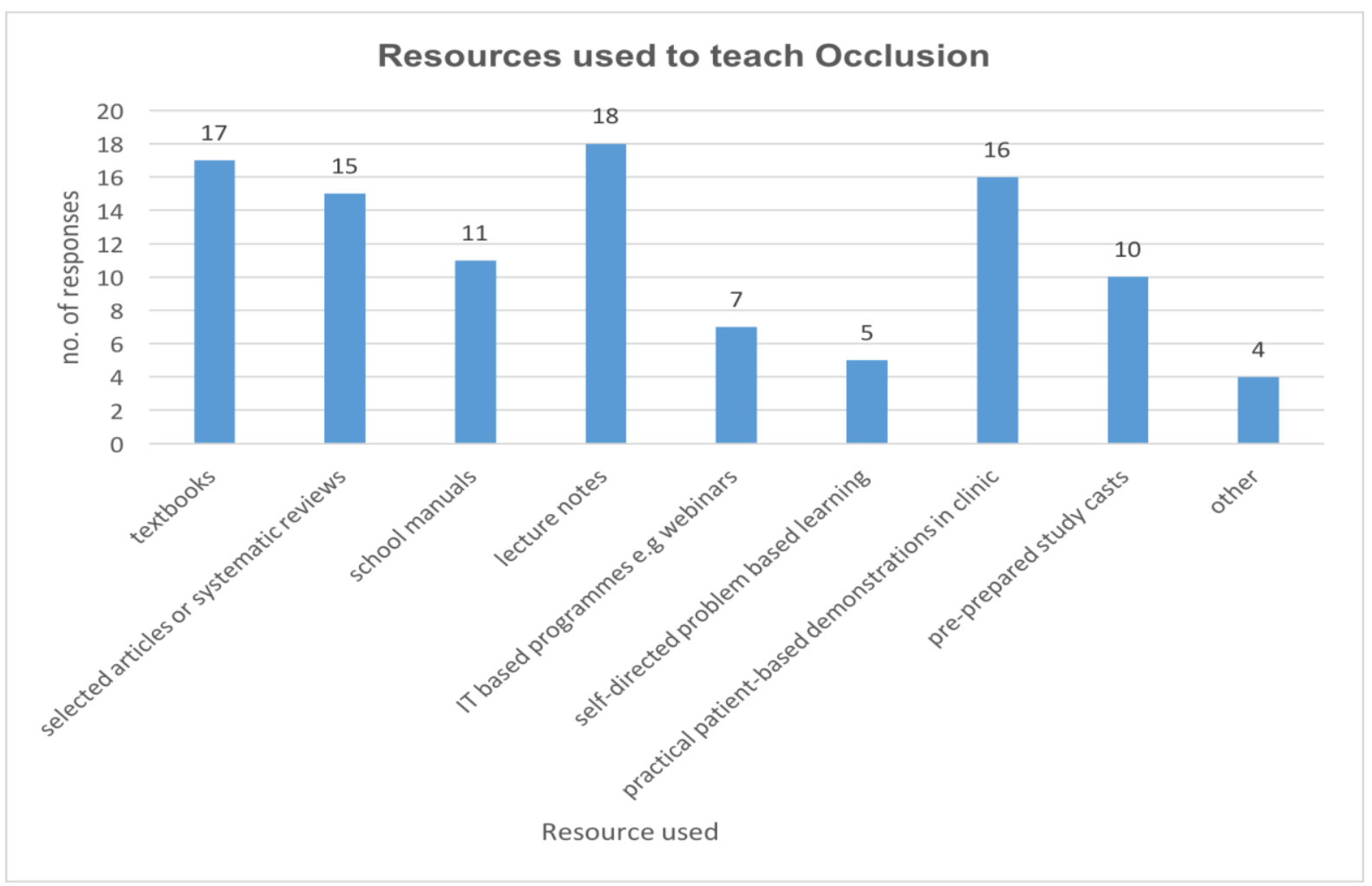

Figure.3. Resources used to teach occlusion

All schools (100\%) reported using lecture notes to teach occlusion. The schools reported using a number of other resources to teach occlusion (See Figure 3).

The most commonly recommended occlusion textbook was 'Applied Occlusion, Quintessentials of Dental Practice' (Wassell, Naru, Steele, Nohl, 2008, London, Quintessence) which was recommended by nine schools (50\%).

All 18 schools (100\%) reported teaching students to use a facebow and record jaw relations. From the interviews, it appears that facebows are used as an occlusion learning resource with students generally practicing taking records on each other before they start treating patients. One respondent cited a view that facebow records were not used in an extramural setting reporting that 'facebow records only happen in the dental hospital'.

There was a variable response regarding the extent to which the record of jaw relations occurs with some schools using them for each patient case, whereas others acknowledged that records of jaw relations are not used and 'that's something that needs work on'. 
In the interviews, schools reported that the topics covered begin with basic concepts with a gradual increase in the complexity of concepts taught. Tutorials were used to practically demonstrate techniques such as facebow record to students. A number of respondents reported that case-based teaching is used to integrate occlusion teaching with one respondent reporting that 'it's only when they start applying the theoretical knowledge that they start to grasp topic relevance'.

A common theme identified was the variable usage of occlusion teaching resources within and between dental schools. Eleven schools (61\%) reported that semi-adjustable articulators were routinely used by students to treatment plan cases and/or carry out an occlusal exam. Nine schools (50\%) reported that students used semi-adjustable articulators to treatment plan cases and/or carrying out single unit fixed prosthodontics, while this figure rose to 17 schools (94\%) when carrying out multiple units of fixed prosthodontics. Data from the subsequent interviews triangulates the research findings that there is variable usage of articulators and articulator type used amongst the schools.

Seventeen schools (94\%) reported that they taught the indications and uses of occlusal splints or similar devices, while one school (6\%) stated that they did not teach this. When asked to elaborate on the teaching of splints and temporomandibular disorder (TMD) in the interviews, the responses given suggested variable and ad-hoc teaching on the concept of occlusion and splints. Some schools report students being given a live demonstration of the different stages of splint construction. However, most schools surveyed responded to the effect that 'other than lectures, it wouldn't be formally taught'. 
iv) Level of preparedness for practice of new dental graduates

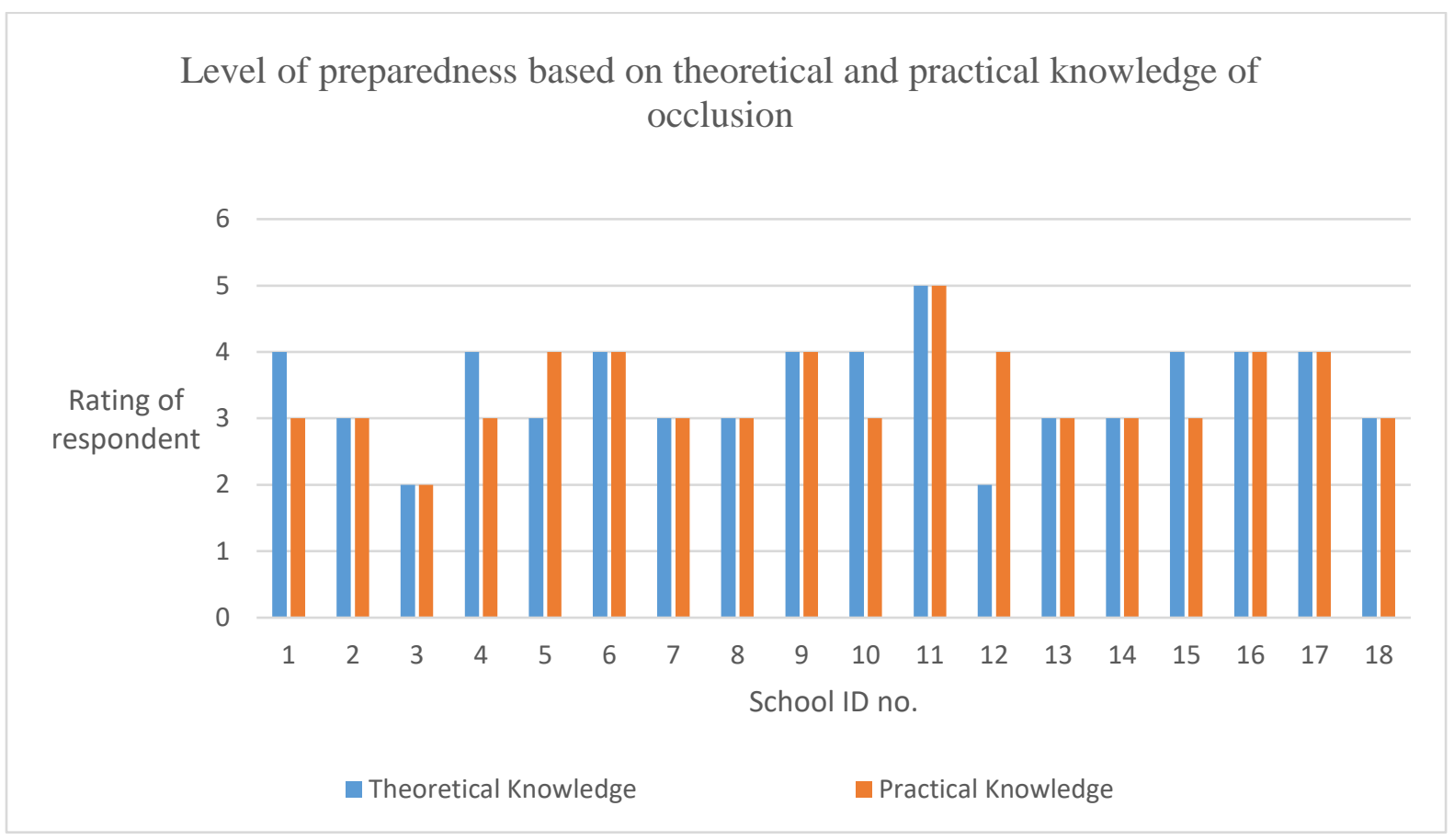

Figure.4. Level of student preparedness based on theoretical and practical knowledge of occlusion

A 5 point Likert scale was used, where 1 was 'poorly prepared' and 5 was 'very well prepared', to assess competency relating to how well prepared respondents felt students were to put into practice the concepts learnt. The median rating was 3.5 for theoretical knowledge and 3 for practical knowledge. As per the rating scale and the accompanying verbal measure of preparedness, this would suggest that respondents viewed graduating students to be somewhere between 'quite prepared' and 'well prepared' based on their theoretical knowledge of occlusion, and 'quite well prepared' based on their practical knowledge (See Figure 4).

Qualitative data enhanced this finding by reporting on the difficulty of determining occlusion competency because of non-uniform student exposure where 'it's always difficult to assess because each individual student, depending on their experience on the clinics and their level of engagement is going to be different'. 
v) Assessment of occlusal knowledge/ skill

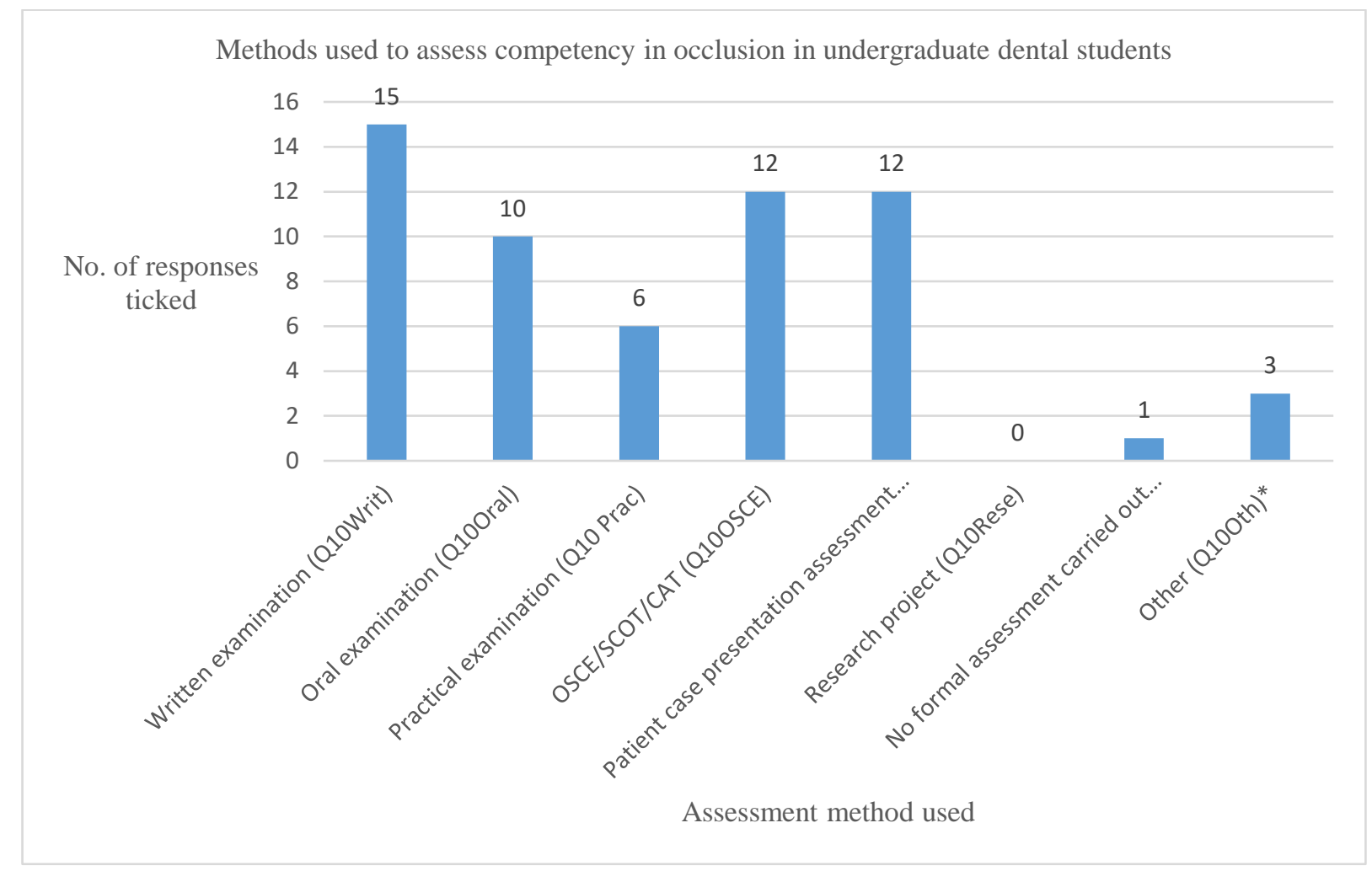

Figure.5. Methods used to assess competency in occlusion in undergraduate dental schools

Written examinations were used by fifteen schools (83.33\%) to assess competency in occlusion. A number of other methods were used to assess competency (See Figure 5).

The follow-up interviews developed this data reporting that MCQ and single-best answer clinical scenarios are common summative written assessments where 'part of the question will be mapped to make sure it covers the occlusion', that occlusion-based OSCEs and clinical management of seen and unseen cases where how occlusion was managed is discussed' to determine occlusion competency. 


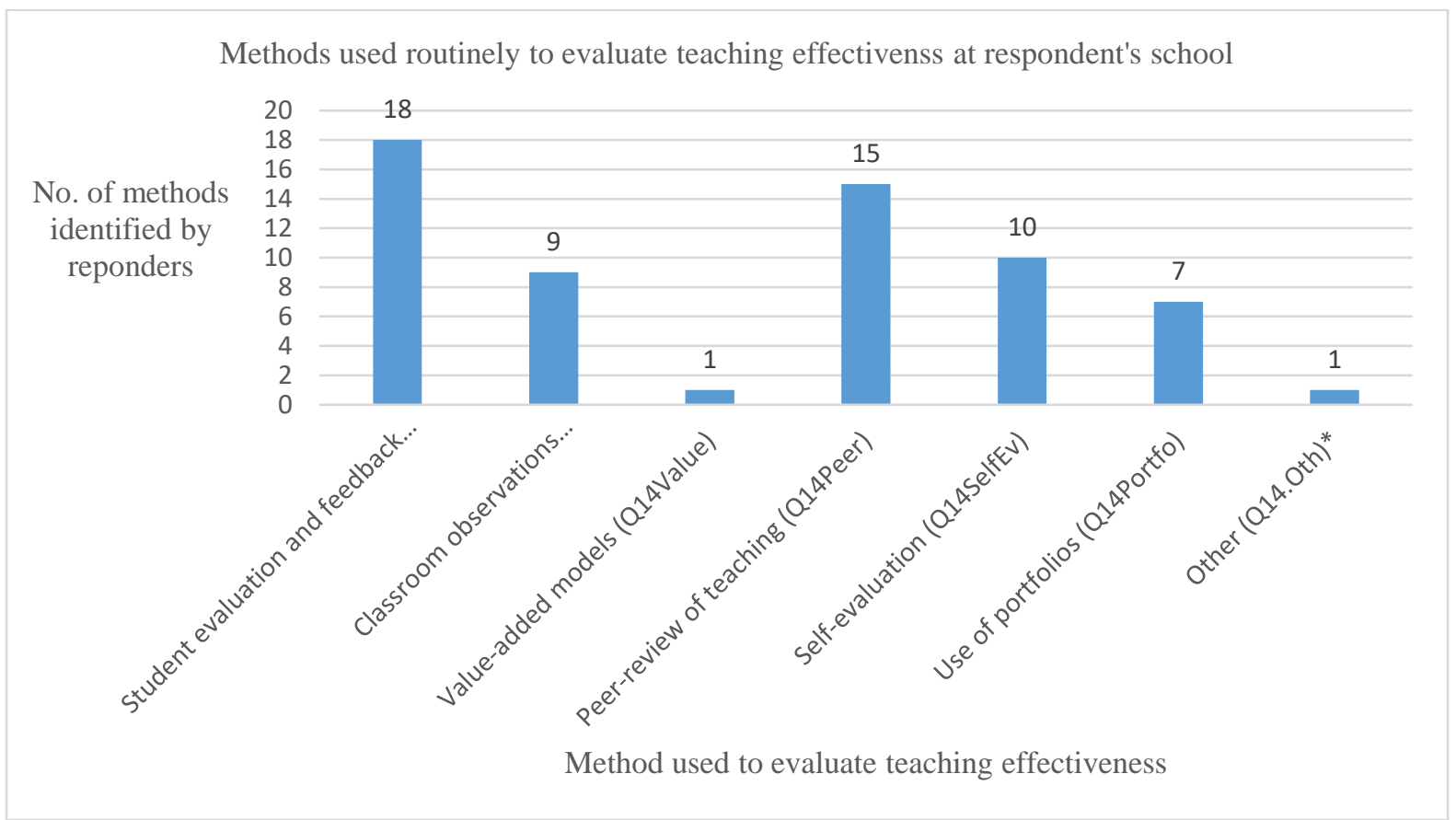

Figure.6. Methods used routinely to evaluate teaching effectiveness at respondents' schools

All 18 schools relied on student feedback to evaluate teaching. A number of other methods were reported to evaluate teaching (See Figure 6).

The interview responses suggested a variable exposure to peer-review between the schools, with some schools reporting that 'every member has peer reviews in their teaching to make sure it's appropriate and fit for purpose', while others stated that 'in theory we have it, but it's entirely minimal'.

Respondents identified the importance of and reliance on student feedback in evaluating teaching, where: 'students are our customers now, their feedback is taken very, very seriously by the school and the university'. The responses also illustrated the role of student performance in the self-evaluation of teaching strategies by 'identifying areas of weakness of student understanding. 


\section{vii) Barriers to teaching occlusion}

Five schools (28\%) felt that there was insufficient time devoted to teaching occlusion in their schools, while 13 schools (72\%) felt it was sufficient.

10 of the 18 schools (56\%) reported encountering barriers to the teaching of occlusion, while 8 schools (44\%) reported no barriers. The barriers identified were: availability of staff, competence of part-time staff, an overcrowded curriculum and lack of time.

\section{DISCUSSION}

The data collected from the two research instruments provided a clear insight into the teaching of occlusion in undergraduate dental schools in the UK and Ireland, and highlighted the variations which existed between these schools.

\section{Variability in Teaching and Teaching Strategies}

In line with previous studies ${ }^{7,8}$, this research suggests that in many dental schools, occlusion is taught within multiple disciplines rather than as a stand-alone subject. The risk with this fragmented approach is that occlusion may be taught from the 'biased viewpoint of one discipline, or more confusingly, been given dogmatically by multiple departments with conflicting philosophies" 7 .

The difficulty in estimating the percentage of time devoted to teaching occlusion by some respondents suggests a degree of confusion in identifying where occlusion is taught in the curriculum. The qualitative data collected at interviews, in this research corroborate this view. This disjointed approach suggests that while some schools have adopted an integrated multidisciplinary approach, there is a lack of coordination between the disciplines.

This confusion regarding delivery is further corroborated by the variable responses provided concerning the number of hours spent teaching occlusion.

Occlusion is a concept that requires reflective critical thinking and problem-solving skills to understand the concepts involved, rather than the 'psychomotor skills of operative dentistry'. This lack of coordination may adversely affect students' perception of occlusion if students are not exposed to the topic in an integrated conceptual manner. 
This research reports no/ minimal teaching dedicated to occlusion in the first year. In some schools this also extended to the second year. It has been suggested that failure to 'recognize the interdependence of all segments of dentistry ${ }^{10}$ leads to polarization, and that this polarization can be avoided by 'developing multidisciplinary coordinated cores of instruction"7. If as thus suggested occlusion is an integral building block to most restorative disciplines, it would seem prudent that students were exposed as early as possible to occlusal concepts to facilitate their comprehension of this and associated topics. If students are taught to understand the relevance of occlusion, thinking critically and applying it to the disciplines that they practice, their understanding of the topic will be enhanced.

The variability in teaching delivery may be mitigated if occlusion teaching was delivered by a single occlusion department with input from other clinical and basic science departments with its' own director as previously recommended ${ }^{11}$. This research reaffirms the need for a dedicated key stakeholder to oversee coordinated delivery of this subject.

\section{Variability in resource use}

The research findings corroborate those from comparable studies, concerning the lack of consistency regarding the use of articulators in UK dental schools ${ }^{12}$.

The research reporting the variable and ad-hoc nature of teaching on occlusal splints and TMD is corroborated by comparable available literature ${ }^{7}$.

The study reports on the variable use of resources used to teach occlusion and recommends that schools revisit the resources available, and their application to occlusion teaching to enable students to grasp practical applicability of occlusion.

\section{Assessment of student competency}

This research reports that multiple methods of student assessment are employed based on the principles of triangulation to ensure competency, as is advocated ${ }^{13}$. However, it is not clear from the data gathered if the methods used have been employed in a coordinated manner to ensure triangulation. Respondents also reported on the challenge of ensuring students' competency, when exposure to occlusion was non-uniform. It has been reported that students perceive themselves more competent in tasks they more frequently perform ${ }^{14}$. 
The researcher recommends that all schools adopt a triangulated approach with newer methods of competency assessment to ensure that students are competent in occlusion and able to utilise their problem-solving skills to critically evaluate clinical scenarios.

\section{Evaluation of teaching}

This research identified the commonly employed methods for teaching evaluation with findings consistent to those previously reported ${ }^{15}$. This study highlighted the 'huge emphasis' given to student evaluation of teaching effectiveness which is consistent with this research. The comment reported by one school which noted that 'students are our customers now' implies a transactional nature of education where students are seen to have purchasing power and influence. The authors query whether students should be perceived in a dominant role as consumers rather than as investors in dental skills education and training. Recent research has looked at the role of students as consumers in Science, Technology, Engineering and Mathematics (STEM) subjects and how this may affect performance ${ }^{16}$.

\section{Barriers to teaching occlusion}

This study reported the link between ad-hoc exposure of students to occlusion and poor perception of this practical topic. The challenges of ensuring student exposure when faced with increasing student numbers and reduced clinic time, compared with previous cohorts has been reported ${ }^{17}$. In the era of competency-based curricula a horizontal curriculum structure as has been outlined would allow students to be exposed to integrated learning modules focusing on specific concepts, rather than a discipline-led structure, at an earlier stage in their teaching ${ }^{18}$. This earlier exposure would enable students to practically apply these concepts as they learn, facilitating better retention of these skills.

The study recognised the challenge of facilitating student exposure where there is a lack of staff with suitable expertise available. The authors recommend that schools identify this barrier to teaching occlusion, addressing it by seeking to recruit staff with this expertise and through continuing professional development of existing staff to improve the quality of learning for students.

The authors proposed coordination of occlusion teaching would ensure harmonization of topics covered and avoid any duplication of teaching. This may also address the limited time available, identified as a barrier to teaching occlusion. 


\section{CONCLUSION}

This study identified the variability in hours reported, resources and assessment methods used between the schools in teaching occlusion to undergraduate dental students in the UK and Ireland. Number of hours reported teaching occlusion ranged from 11 to 310 hours between schools.

While schools instruct students on occlusal concepts and occlusal terminologies, the integration of the knowledge provided by the different disciplines appears to be poorly coordinated. Students' perception of occlusion appears to be influenced by their exposure to the topic, and the interviews conducted suggest that this exposure is variable both within and between the schools.

This study would have benefitted from triangulation with a separate set of data from students' perspectives on the teaching of occlusion, and the authors recommends that such a study would allow comparison between educator and student views regarding this teaching.

\section{Declaration of Interests:}

None of the authors have any declaration of interests to report.

\section{Acknowledgements:}

We are extremely grateful to all individuals from all undergraduate dental schools in the UK and Ireland, who volunteered their time and expertise to complete the questionnaire and to participate in the interviews. Without their encouragement and assistance this study would not have been possible.

\section{References}

1. The General Dental Council. Standards for Education. Standards and requirements for providers. London, General Dental Council, 2015. 
2. The General Dental Council. Preparing for Practice. Dental team learning outcomes for registration. London, General Dental Council, 2015 revised edition.

3. The Dental Council of Ireland. Learning outcomes. Dublin, The Dental Council of Ireland, 2013.

4. Plasschaert AJM, Holbrook WP, Delap E, Martinez C, Walmsley AD. Profile and competences for the European dentist. Eur J of Dent Educ 2005: 9: 98-107.

5. Davies S, Gray R. What is occlusion? Br Dent J 2001: 191: 235-238, 241-245.

6. Türp JC, Greene CS, Strub JR. Dental occlusion: a critical reflection on past, present and future concepts. J Oral Rehabil 2008: 35: 446-453.

7. Esposito CJ, Farman AG, Veal SJ. Occlusion in the dental curriculum: 1980-1981. J Prosthet Dent 1983: 49: 419-426.

8. Lee DJ, Wiens JP, Ference J, Donatelli D, Smith RM, Dye BD, Obrez A, Lang LA. Assessment of occlusion curriculum in predoctoral dental education: report from ACP Task Force on Occlusion Education. J Prosthodont 2012: 21: 578-587.

9. Cohen SN and Silvestri AR. Teaching clinical problem solving in preclinical occlusion courses. J Dent Educ 1979: 43: 7: 353-355.

10. Mann WV. Emphasis-Dental education. J Am Dent Assoc 1981: 102: 5: 625.

11. Weisgold AS. Teaching a core course in occlusion. J Prosthet Dent 1975: 33: 1: 89-95.

12. Hindle JR and Craddock JL. The use of articulators in UK dental schools. Eur J Dent Educ 2006: 10: 197-203.

13. Albino JE, Young SK, Neumann LM et al. Assessing dental students' competence: best practice recommendations in the performance assessment literature and investigation of current practices in predoctoral dental education. J Dent Educ 2008: 72: 12: 1405-1435. 
14. Whitney EM, Walton JN, Aleksejuniene J et al. Graduating dental students' views of competency statements: importance, confidence, and time trends from 2008 to 2012. J Dent Educ 2015: 79: 3: 322-330.

15. Jahangiri L, Mucciolo TW, Choi M et al. Assessment of teaching effectiveness in US dental schools and the value of triangulation. J Dent Educ 2008: 72: 6: 707-718.

16. Bunce L, Baird A and Jones SE. The student-as-consumer approach in higher education and its effects on academic performance. Stud High Educ 2017: 42: 11: 1958-1978.

17. Martin N, Fairclough A, Smith M and Elis L. Clinical educators' views on the quality of undergraduate clinical restorative dentistry in the UK and ROI. Eur J of Dent Educ 2011: 15: 4: $216-222$.

18. Hendricson WD and Cohen PA. Oral healthcare in the $21^{\text {st }}$ Century: Implications for Dental and Medical Education. Acad Med 2001: 76: 12: 1181-1206. 